\title{
Reduced Dump Load Strategy with FDI using FSS in Micro-Hydel Generating Systems
}

\author{
B. Anil Kumar ${ }^{1}$, R.Raja Singh ${ }^{2, *}$, Harshit Mohan ${ }^{1}$, and Thanga Raj Chelliah ${ }^{1}$ \\ ${ }^{1}$ Hydropower Simulation Laboratory, Department of WRD \& M, IIT Roorkee, India \\ ${ }^{2}$ Advance Drives Laboratory, Department of Energy and Power Electronics, VIT Vellore, India
}

\begin{abstract}
Micro-hydel plants are used in micro-grid or off-grid areas where there is an adequate availability of hydro potential. In general, micro-hydel systems are embedded with synchronous or asynchronous generator based electronic load controller (ELC) to have better frequency stability. Conventional ELC operate the generator with full load capacity regulating the generator output voltage and frequency. The conventional controller has a demerit of less efficiently. This paper presents a reduced dump load strategy (RDLS) with fault detection and isolation (FDI) for reliable operation of micro-hydro generators. Proposed strategy protects the system from load disturbances and isolates the system during line fault and sensor fault. Reduced dump load strategy with FDI enhances the machine's lifespan and protects the system from catastrophic failure. Practical implementation of developed reduced dump load strategy using Full Spectrum Simulator (FSS) with 3 HP generator is presented in this paper. The presented methodology includes coding based FSS for controlling the dump load and switching operation.
\end{abstract}

\section{Introduction}

The centralized power distribution system was incapable to deliver cheap and reliable electricity to consumers in geographically isolated areas. Hence, the distributed power generation started assisting centralized power distribution system that gives rise to microgrid. According to International Energy Agency, 1.1 billion world population lack access to electricity in 2015 and has estimated that the number will raise to 1.2 billion by year 2030 due to high population growth rate [1]. In India 0.27 billion people are without electricity access in 2015. In a vision towards $100 \%$ electrification the Indian government has initiated schemas such as JNN solar mission, and Pradhan Mantri Gram Vidyut Yojana in addition with Deen Dayal Upadhyaya Gram Jyoti Yojana in rural areas and Integrated Power Development Scheme in urban areas. As of 2018, $88 \%$ of total households of India are connected to grid or are electrified autonomously with micro-grid [2].

Stand-alone micro scale renewable source power generation has gained more attention in electrifying rural areas of developing countries. Micro scale hydro potential power available seems to be promising to meet demand in isolated areas. Isolated micro hydro plant can be controlled either by governor system or by using electronic controllers to keep its

\footnotetext{
* Corresponding author: rrajasingh@vit.ac.in
} 
frequency/voltage constant. The revolutionary advancement in power electronics have enhanced the system operating efficiency. Generally, micro-hydel power plant utilizes selfexcited synchronous/asynchronous generators for power generation. For system capacity below $30 \mathrm{~kW}$ induction generators are economically viable [3]. The generators output voltage and frequency depends on connected load and shaft speed respectively. In India the operating voltage and frequency is $440 \mathrm{~V}$ and $50 \mathrm{~Hz}$ respectively. During generator operation any discrepancy in connected load fluctuates the generator output voltage and frequency in addition with mechanical vibration, acoustic noise and temperature rise, which altogether decline the efficiency and generator's life [4]. Electronic load controller (ELC) plays a key role in mitigating these effects at generators side. Typically, ELC consists of dump loads with a control mechanism usually connected in parallel to the main load. Moreover, usage of dump load ELC results in power wastage. For that reason, ELC is not easily recommended by investigators, generally in case of autonomous power generation system. Instead of dump load, energy storage systems are recommended. Moreover, employing energy storage system involves more investment and maintenance cost.

In existing dump load strategy, generator is more vulnerable to electrical, mechanical and thermal stresses, as it is continuously fully loaded. In addition, the sensor faults and open circuit faults in the system leads to generator over loading eventually causing temperature rise in windings which in worst condition may result in system collapse. There are numerous techniques adopted for detecting and isolating the sensor faults and to protect the system from catastrophic failures. Focusing on aforementioned demerits, this paper presents a reduced dump load strategy (RDLS) with fault detection and isolation (FDI), which can provide significant reduction in power wastages and enhances the generator life span. Controlling and monitoring of the proposed strategy is carried out using full spectrum simulator (FSS). The FSS simulator is an indigenously developed system by power electronics group C-DAC (T) and IIT Bombay has both off-line simulation and real-time simulation capabilities at allow reasonable cost. As well, it is easy to configure for any other custom applications.

\section{Reduced dump load strategy}

The core purpose of RDLS is to regulate the voltage and frequency of the generator by diverting surplus power to dump load during a reduction in the main load by maintaining power generation at an acceptable level throughout. Primarily, electronic dump load control was introduced for run-of-river scheme based micro hydro plants in view to reduce the installation cost by replacing hydraulic governor. As mention earlier operation of self-excited asynchronous generators (SEAG) in standalone situations inherent poor voltage regulation which is the major bottleneck in its applicability.

To mitigate the power wastage and thermal effect a RDLS is applied in micro-hydel operation. In RDLS the dump load is limited to 80 percent of full load. Reduction in dump load for micro hydro application has been presented in [4]. In this paper RDLS program is compiled in FSS which calculate the performances related parameters continuously and follow the steps shown in Fig. 1. Supplementary dump load to be added which is proportional to changing main loads is calculated by using (1), (2) and (3) [5].

$$
\begin{array}{r}
\mathrm{Z}_{\mathrm{c}}^{\text {main }}=\frac{\mathrm{V}_{\mathrm{s}}}{\mathrm{i}_{\mathrm{s}}} \\
\mathrm{Z}_{\mathrm{c}}^{\text {dump }}=\frac{\mathrm{Z}_{\mathrm{c}}^{\text {main }} \times \mathrm{Z}^{\text {main }}}{\mathrm{Z}_{\mathrm{c}}^{\text {main }}-\mathrm{Z}^{\text {main }}} \\
\mathrm{i}_{\mathrm{c}}^{\text {dump }}=\frac{\mathrm{V}^{\text {ref }}}{\mathrm{Z}_{\mathrm{c}}^{\text {dump }}}
\end{array}
$$


Where, $\mathrm{Z}_{\mathrm{c}}^{\text {main }}$ and $\mathrm{Z}_{\mathrm{c}}^{\text {dump }}$ are main load and dump load impedance from sensed voltage and current $\mathrm{V}_{\mathrm{s}}, \mathrm{i}_{\mathrm{s}}$ respectively. $\mathrm{Z}^{\text {main }}$ is the total main load connected to the system, $\mathrm{i}_{\mathrm{c}}^{\text {dump }}$ is calculated dump load current and $V^{\text {ref }}$ reference voltage. Program is carved for FSS to calculate $\mathrm{i}_{\mathrm{c}}^{\text {dump }}$ and is embedded with 80 percent of the full load current. PWM pulses for controlling IGBT operation is obtained by triangular carrier signal $i_{\text {cr }}$ generated by FSS and the modulation signal $i_{m d}$ obtained from $i_{c}^{\text {dump }}$ after proper controlling. Coding for generation of controlling PWM pulses is done in FSS. The switching logic, which is followed is given in (4).

$$
\text { If, } \mathrm{i}_{\mathrm{md}}>\mathrm{i}_{\mathrm{cr}}, \mathrm{s}=1 \text { and when } \mathrm{i}_{\text {md }}<\mathrm{i}_{\mathrm{cr}}, \mathrm{s}=0
$$

Where, 's' represents the state of IGBT switch, when $s=0$, IGBT switch is open and when $\mathrm{s}=1$, switch is close.

\section{Fault detection and isolation}

Fault detection and isolation is carried out to save the system from undergoing catastrophic consequences during a fault. The severity of the fault depends upon the sensitivity of adopted control system. Many literatures discuss concepts of dump load in view of achieving stable operation but very few have focused on the protection regarding various power quality disturbances and sensor faults [6]-[8]. FDI and identification of faulty sensors are considered for improving redundancy of the system. For the ease analysis, only open circuit fault and open circuit sensor fault are considered and the system is isolated during these faults. Faulty sensor detection generally depends on hardware redundancy, which is costlier and cumbersome, whereas analytical redundancies which are based upon complex algorithms are hard to apply for real time implementation. This paper adopted fault diagnostic technique

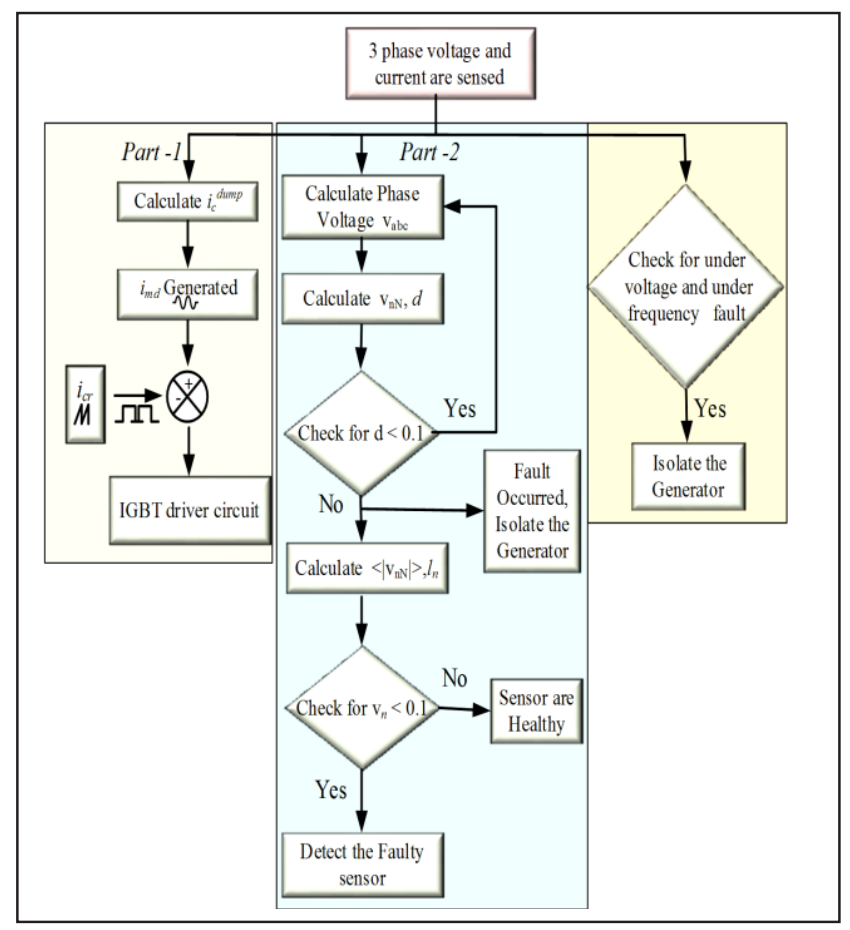

Fig. 1. Adopted control methodology. 
detects OC fault and also locate the faulty sensor by measuring three phase voltages. The process for controlling dump load and FDI is represented in a flow diagram shown in Fig. 1.

\section{Experimentation}

Implementation of the proposed system, Fig. 2(b), consist of a $3 \mathrm{HP}$ squirrel cage induction generator (SCIG) coupled with a 5 HP DC motor which functions as a prime mover. SCIG is connected to main load and dump load through switches. A delta connected capacitor bank is used to provide necessary reactive power to SCIG. In addition, RDLS setup comprises of voltage and current sensors for sensing and feeding the generator output signal to FSS controller to control the connected resistive load which acts as a dump load. FSS simulator which is used for controlling and monitoring of the system. FSS mainly has two parts, firstly windows operating system based host computer for pre-processing and secondly Linux operating system based real time simulation execution on FSS hardware. Moreover, for analysing the generator performance, the output electrical quantities are measured using power quality analyzer. The input speed and power is measured using tachogenerator and spring dial. The schematic diagram of the experimental arrangement is shown in Fig. 2(b).

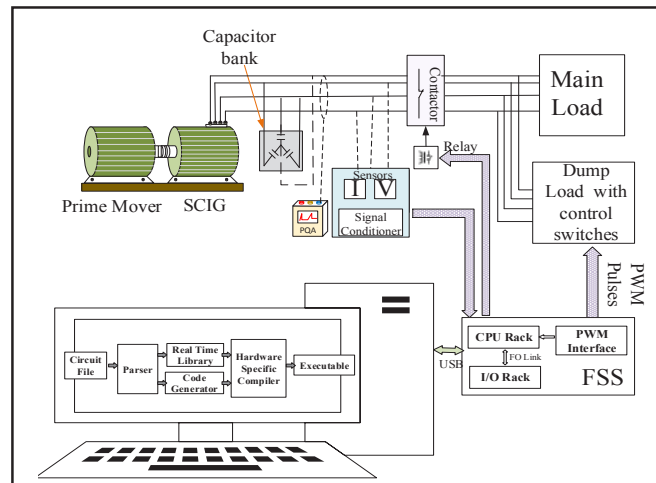

(a) Schematic diagram.

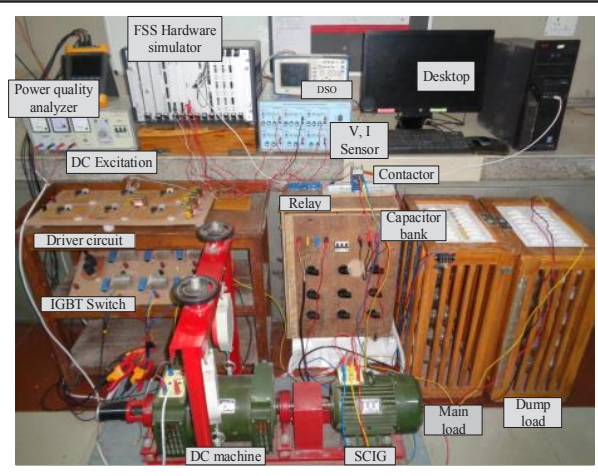

(b) Experimental arrangement

Fig. 2. Schematic diagram of experimental arrangement.

\section{Lifespan estimation of generator}

Thermal effect is more predominant among many factors that affect the life span of generator [9]. Every $10^{\circ} \mathrm{C}$ rise above the generator design temperature reduces its lifespan by 50 percent. This $10^{\circ} \mathrm{C}$ rule for half-life in electrical machine depends on the employed insulation properties. For thermal analysis, the utilized induction generator is operated at full load and 0.8 p.u. load for a specific time duration ( $2 \mathrm{hrs}$. interval) and their thermal variation is measured by high precision thermal analyzer. From the results shown in Fig. 3, it is observed that the fully loaded induction generator produces $8.4 \%$ more temperature than loaded at 0.8 p.u. Following assumption has been considered for estimating the lifespan of the generation in steady state undergoing temperature variation.

1) Generator stator winding lifespan is assumed to be $50,000 \mathrm{hrs}$

2) Generator winding temperature is assumed to be $20^{\circ} \mathrm{c}$ greater than the machine surface temperature

3) Generator winding temperature is assumed to be $10^{\circ} \mathrm{c}$ lesser than the machine insulation temperature. 


$$
L_{a}=L_{r} C^{-\left(\frac{\Delta T}{\Delta T_{b}}\right)}
$$

Actual lifespan of generator winding is estimated using (5) were $L_{a}$ is the actual estimated lifespan of generator winding, $L_{r}$ is the rated winding lifespan, $C$ is a constant taken as 0.5 , $\Delta T_{b}$ being the base difference between insulation and winding temperature taken as $10^{\circ} \mathrm{c}$, and $\Delta T$ is the raise in temperature above the rated design temperature got from $\Delta T=\Delta T_{a}-\Delta T_{r}$. Were $\Delta T_{a}$ is the actual temperature rise above the rated design temperature, and $\Delta T_{r}$ being the temperature rise above the ambient air at rated load. From above equation machine lifespan is computed and it has been found that the reduced dump load ELC increases the generator winding lifespan by 43.4 percent.

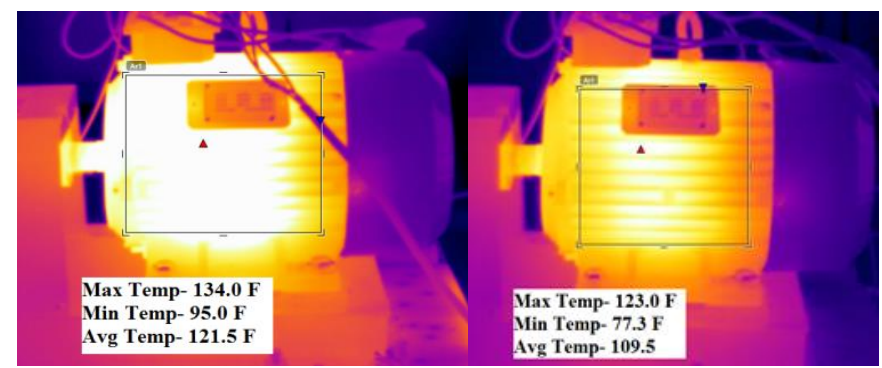

(a) 1 p.u. load

(b) 0.8 p.u. load

Fig. 3. Temperature variation under reduced dump load and full load in ${ }^{\circ} \mathrm{F}$.

\section{Results and discussion}

In case of fault detection, the prescribed above steps FSS reset the triggering value of relay which in turn with the help of a contactor isolate the system. The logic for FSS to reset the value is shown in Table 1.

The efficiency curve for induction generator is experimentally obtained according to the IEEE standard $115^{\mathrm{TM}}-2009$. The dump load capacity is equivalent to the main load, but to mitigate the power wastage and thermal effect the dump load current is limited to 80 percent of the full load current as limiting dump load current provide a better performance of the machine. It is observed that the machine acquires maximum efficiency at 0.8 p.u. load. During off peak periods, dump load gets engaged in maintaining stable operation of the SCAG.

Table 1. FSS Output

\begin{tabular}{|c|c|c|c|}
\hline Fault detection & Limiting value & \multicolumn{2}{|c|}{ FSS Hardware } \\
\hline \multirow[t]{2}{*}{ OC Fault } & $\mathrm{d}<0.1$ & \multicolumn{2}{|c|}{ Set } \\
\hline & $d>0.5$ & \multicolumn{2}{|l|}{ Reset } \\
\hline \multirow[t]{2}{*}{ Sensor Fault } & $\mathrm{V}_{\mathrm{n}}<0.1$ & \multicolumn{2}{|l|}{ Set } \\
\hline & $\mathrm{V}_{\mathrm{n}}>0.5$ & \multicolumn{2}{|l|}{ Reset } \\
\hline \multirow[t]{2}{*}{ Under Voltage } & Up to $5 \%$ & Set & \multirow{4}{*}{$\begin{array}{l}\text { When } \\
\mathrm{i}_{\mathrm{c}}^{\text {dump }} \text { has max } \\
\text { or min value }\end{array}$} \\
\hline & Above 5\% & Reset & \\
\hline \multirow[t]{2}{*}{ Under Frequency } & Up to $2.5 \%$ & Set & \\
\hline & Above $2.5 \%$ & Reset & \\
\hline
\end{tabular}




\section{Conclusion}

Analysing the plotted results concludes that the variation in voltage and frequency stand within 10 percent and 3 percent respectively during the change of load from 1 p.u. to 0.8 p.u. which is under permissible limits as per IEEE standard $1250^{\mathrm{TM}}-2011$. Table 1 shows the limiting values for FSS for controlling switching action of contactor.

A simple and cheap approach for RDLS with FDI using FSS for real time application in micro hydel-micro grid has been adopted successfully. Adopted methodology protects the system from all most every power quality disturbance with considerable power saving by limiting the added dump load to 80 percent. From the half-life rule in electrical machine, it is observed that by adopting RDLS machine lifespan has improved by $43.3 \%$. For maintaining system stability FDI is achieved under open circuit fault, in addition to it the faulty sensor is also identified.

\section{References}

1. Energy Access Outlook 2017 [online] Available at: https://www.iea.org/access2017/, (2018)

2. Rural electrification [online] Available at: https://en.wikipedia.org/wiki/Rural_ electrification, (2018)

3. S. Singh, M. L. Azad and A. Kumar, International Conference on Innovation and Challenges in Cyber Security, Noida, 300-303, (2016)

4. R. Panda, R. R. Singh and T. R. Chelliah, IEEE 11th International Conference on Power Electronics and Drive Systems, Sydney, 352-357, (2015)

5. E.Torres, F.Chan, J.Ramirej, A.Como, 12th International Power Electronics Conference, $61-66,(2010)$

6. F. R. Salmasi and T. A. Najafabadi, IEEE Trans. Energy Convers., 959-966, 26 (2011)

7. N. M. A. Freire, J. O. Estima and A. J. M. Cardoso, IEEE Transactions on Industry Applications, 1206-1214, 50 (2014)

8. R. Raja Singh, B. Anil Kumar, D. Shruthi, Ramraj Panda, C. Thanga Raj, Engineering Science and Technology, an International Journal, (2018)

9. F. Kielmann and M. Kaufhold, IEEE Transaction on Dielectrics and Electrical Insulation, 1373-1377, 17, (2010) 